\title{
Very low-birth-weight infants with congenital cardiac lesions: Is there merit in delaying intervention to permit growth and maturation?
}

\author{
Edward J. Hickey, MD, ${ }^{\mathrm{a}}$ Yaroslavna Nosikova, BSc, ${ }^{\mathrm{a}}$ Hargen Zhang, MD, ${ }^{\mathrm{a}}$ Christopher A. Caldarone, MD, ${ }^{\mathrm{a}}$ \\ Lee Benson, MD, ${ }^{\mathrm{b}}$ Andrew Redington, MD, ${ }^{\mathrm{b}}$ and Glen S. Van Arsdell, $\mathrm{MD}^{\mathrm{a}}$
}

\begin{abstract}
Background: Low birth weight and prematurity and are known risks for mortality in congenital heart lesions. It is not known whether risks of delayed intervention are offset by benefits of growth and maturation. We explored this question.
\end{abstract}

\begin{abstract}
Methods: All 1618 infants admitted to our institution within 30 days after birth for a congenital heart defect since 2000 were analyzed. Birth details and admission progress notes were detailed on all. For infants requiring cardiac interventions, clinical conference records and progress notes enabled their management to be classified as either USUAL (normal timing and mode of intervention) or DELAYED (intentional delay for growth/maturation). The survival implications of birth weight and prematurity were examined via parametric multiphase methodology with bootstrap resampling. Subsequently, the impact of DELAYED management was sought in propensity-adjusted and multivariable time-related models.

Results: Low birth weight is a strong, robust and independent predictor of death within the first year of life $(P<.0001 ; 99.6 \%$ bootstrap resamples). The relationship is nonlinear with an inflection point at approximately $2.0 \mathrm{~kg}$, below which decrements in survival are increasingly pronounced. Prematurity is also associated with poor outcome but less reliably so $(P<.0001 ; 53 \%$ resamples $)$; its variance appears partially mitigated by colinearity with multiple factors including diagnosis and chromosomal aneuploidy. Of the 149 infants with birth weight less than $2.0 \mathrm{~kg}$ (highest risk and most likely to receive delayed care in this cohort), care was USUAL in 34 and DELAYED in 46. The remaining children received comfort care only (27), were not considered for intervention owing to severe noncardiac problems (12) or were routinely observed for nonurgent lesions (30). Survival between the children weighing less than $2.0 \mathrm{~kg}$ and receiving USUAL or DELAYED care was identical (78\% $\pm 2 \%$ at 1 year; $P=.88$ ), even when adjusted via propensity score $(P=0.65)$ or multivariable analysis $(P=0.55)$. Major determinants of death in this very low-birth-weight population were antenatal diagnosis $(P=.01)$, presence of congenital gastrointestinal defects $(P=.07)$, or lesion type (all higher risk: anomalous pulmonary venous drainage, $P=.03$; pulmonary atresia and intact septum, $P=.05$; and truncus, $P=.01$ ).
\end{abstract}

Conclusions: For very low-birth-weight neonates $(<2.0 \mathrm{~kg})$ with congenital heart defects, imposed delays in intervention neither compromise nor improve survival. Other factors instead appear to account for survival differences, including lesion type, associated noncardiac congenital defects, and antenatal diagnosis. (J Thorac Cardiovasc Surg 2012;143:126-36)

Supplemental material is available online.

\footnotetext{
From the Division of Cardiovascular Surgery, ${ }^{\mathrm{a}}$ Department of Surgery, and Division of Cardiology, ${ }^{\mathrm{b}}$ Department of Pediatrics, University of Toronto, The Hospital for Sick Children, Toronto, Ontario, Canada.

Disclosures: Authors have nothing to disclose with regard to commercial support.

Read at the 91st Annual Meeting of The American Association for Thoracic Surgery, Philadelphia, Pennsylvania, May 7-11, 2011.

Received for publication May 9, 2011; revisions received Aug 19, 2011; accepted for publication Sept 15, 2011; available ahead of print Oct 24, 2011.

Address for reprints: Edward J. Hickey, MD, The Hospital for Sick Children, Room 5288, 555 University Ave, Toronto, Ontario M5G 1X8, Canada (E-mail: edward. hickey@sickkids.ca).

0022-5223/\$36.00

Copyright (c) 2012 by The American Association for Thoracic Surgery doi:10.1016/j.jtcvs.2011.09.008
}

Earn CME credits at

http://cme.ctsnetjournals.org
Low birth weight and prematurity and are known risks for mortality in surgery for congenital heart disease. ${ }^{1,2}$ For these high-risk children, a clinical dilemma exists: whether to pursue early (higher-risk) therapeutic intervention or else impose a period of delay for growth and maturation before (presumably lower-risk) intervention. It is not known whether risks of delay are offset by benefits of growth and maturation.

Because a prospective trial seems unlikely (or impossible), we investigated the influence of low birth weight or prematurity on survival for neonates born with serious congenital heart lesions over the past decade at our institution. Specifically, we aimed (1) to characterize the nature of low 
birth weight and prematurity as risk factors and then (2) to explore the impact of imposed delays on survival for these high-risk children.

\section{METHODS}

\section{Overview}

In this investigation, we studied all neonates (aged $<30$ days) admitted to our institution with structural congenital heart disease over the past 10 years $(\mathrm{n}=1618)$. Birth records were scrutinized for gestational age and birth weight. Gestational age and birth weight were then explored as risk factors for time-related death. For children who subsequently underwent cardiac interventions, clinical conference records were explored for decision-management strategies. Risk-adjusted survival was compared between children in whom intervention was intentionally delayed (DELAYED) versus those in whom usual active management strategies were adopted (USUAL). The study was approved by our institutional research ethics board; however, individual patient consent was not sought because patients were not contacted directly.

\section{Eligibility}

The 1618 study patients were identified from reviewing our institutional cardiology diagnostic database (Figure E1). Over the study period (January 2000-September 2010), 8497 children aged less than 3 months received 35,980 cardiology diagnostic codes during clinical consultations, investigations, or admissions. All 35,980 codes were individually reviewed to identify structural congenital heart disease $(n=4171$ children; eg, ventricular septal defect or coarctation) as opposed to physiologic diagnoses (eg, hypertension or atrial tachyarrhythmia). Isolated patent ductus arteriosus and benign variants of normal (eg, isolated left superior vena cava to coronary sinus) were not included. Individual case notes for all 4171 children were scrutinized to identify only those 1618 whose cardiac diagnosis was partly or wholly responsible for admission within 30 days after birth to any of our cardiology, neonatal, or intensive care services (as a surrogate for the critical nature of the problem). Consequently, our study cohort did not capture subjects with cardiac lesions of a more benign nature managed as outpatients or incidental diagnoses in neonates admitted for unrelated problems.

\section{Data Abstraction}

The 1618 study patients were subjected to a rigorous review of clinical documents including antenatal records, delivery details, admission details, diagnostic echocardiography reports, percutaneous and open surgical interventions, and clinical conference notes. Abstracted data were input into a research database. Last contact dates and status were available on all patients (mean, 3.4 years) to a maximum of 10.3 years.

\section{Analytic Strategy}

A: Impact of prematurity and birth weight on survival. Our initial objective was to investigate the relative impact of prematurity and birth weight on survival. These relationships were explored first by univariate and then by multivariable (risk-adjusted) analyses (Results, section A). The models thus produced allowed us to generate nomograms graphically depicting these nonlinear relationships to identify clinically important "thresholds." In our analysis, birth weight less than $2.0 \mathrm{~kg}$ was identified as a particularly important threshold for risk of death (Results, section A).

B: Classification of management strategy. Having determined birth weight less than $2.0 \mathrm{~kg}$ as a threshold below which survival is particularly poor, the decision management for these 149 neonates was then classified according the strategic intentions documented in clinical conferences or progress notes. Our division holds weekly surgical conferences in which all patients are discussed and decision management is documented. Management strategies were classified as follows: USUAL, OBSERVE, DELAYED, NON-CV, and WITHDRAWN.
USUAL. Early therapeutic intervention according to usual divisional management paradigms in infants of normal weight. Therefore, the child's small birth weight has been disregarded, and management is entirely according to "usual" care strategies adopted by our cardiovascular division (eg, early scheduled repair of neonatal coarctation, early arterial switch within 7 to 10 days for simple transposition of the great arteries, or Norwood operation within 1 to 2 weeks for hypoplastic left heart syndrome). OBSERVE. Early intervention not necessary. Therefore, observation/ expectant management is done in the first instance in accordance with typical divisional management paradigm. Imposed periods of delay for growth are therefore not relevant, inasmuch as the diagnosis does not require early intervention (eg, medical management of stable tetralogy of Fallot until planned repair age of 5 to 6 months, observation of large ventricular septal defect until repair at age 6 months, or observation of unobstructed total anomalous pulmonary venous connection until repair at 6 weeks).

$D E L A Y E D$. Intentional delay in early intervention to permit growth or maturation. Therefore, low birth weight has specifically prompted a deviation from usual divisional management paradigms (eg, 1.4-kg neonate with coarctation maintained on prostaglandin with aim of repairing when $>2.0$ $\mathrm{kg}$, or duct-dependent tetralogy of Fallot maintained with prostaglandin). Children were included if a palliative approach (eg, shunt or band) was pursued that was in contrast to usual divisional management paradigms, specifically, to permit growth.

$\mathrm{NON}-\mathrm{CV}$. Higher priority noncardiovascular conditions dictating clinical care; cardiovascular decision management lesser priority (eg, repair of large ompalocoele delaying intervention for an interrupted arch).

WITHDRAWN. Active management withdrawn and comfort palliative care instigated owing to unfavorable prognosis (eg, trisomy 18 with absent corpus callosum, obstructive total anomalous pulmonary venous drainage, and atrial isomerism).

C: Survival comparisons between USUAL and DELAYED care in high-risk neonates. Time-related survival was compared between children whose management was either USUAL or DELAYED. Comparisons were made using univariate regression and then by risk-adjusted techniques (multivariable regression and propensity adjustment).

\section{Statistical Methods}

Analysis was performed using parametric time-related techniques employing multiple hazard phases ${ }^{3,4}$ using techniques described in detail elsewhere..$^{5}$ All analyses were undertaken with SAS statistical software (SAS Institute, Inc, Cary, NC) using freely available parametric HAZARD macros (www.clevelandclinic.org/heartcenter/hazard). For risk-hazard analyses, variables were tested in a univariate fashion and subsequently multivariable (risk-adjusted) fashion using parametric automated forward stepwise regression. Variables were processed as previously described ${ }^{5}$ and were excluded if associated with fewer than 5 events (deaths) to avoid overdetermination. All continuous variables were tested for transformations that improved model fit. Reliability of variables reaching statistical significance $(P<.05)$ was tested using bootstrap resampling ${ }^{6}$ in which automated random training data sets are generated $(n=1000)$ against which the variables are tested. Inclusion of the variable inmore than $50 \%$ of training data sets is interpreted as an indicator of good reliability. ${ }^{1}$ For propensity adjustment, baseline patient-specific variables were entered into a logistic regression modeling the probability (propensity) of management being USUAL or DELAYED. The logistic model generated a cumulative probability (propensity score) for every child. This propensity score was then inserted into subsequent multivariable regression models to account for subtle baseline differences between the study groups.

Rate of growth was determined by using repeated-measures techniques. Therefore, regression equations are adjusted for changes within individual patients. For this repeated-measures analysis, generalized estimating equations were solved, adjusted for individual patients through autorecessive 


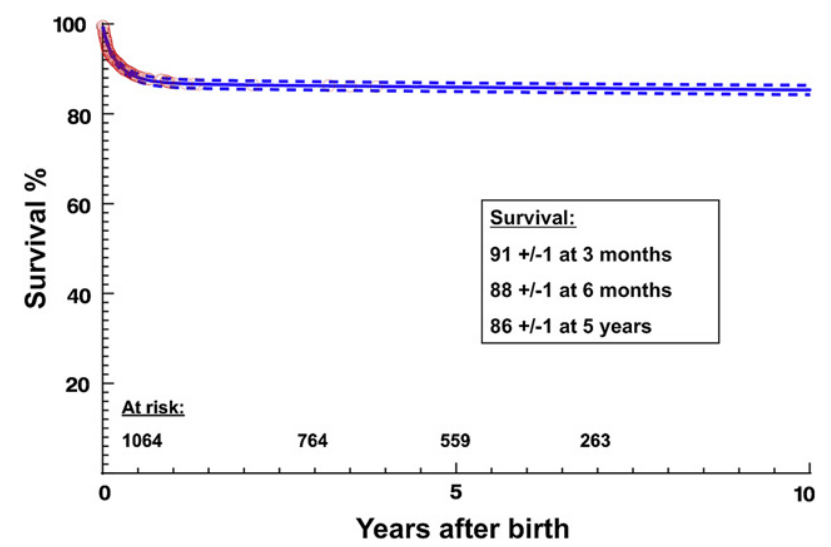

FIGURE 1. Survival from birth in the 1557 study children who were actively managed. The hazard (risk) for death was predominantly early, within the first year after birth. Thereafter, the persisting hazard for death was constant and low ( $<<1 \%$ per year). Circles represent nonparametric estimates at events (deaths), solid lines represent parametric determinants of continuous point estimates, and dashed lines enclose $70 \%$ confidence intervals.

covariance. For descriptive statistics, comparisons were made using either the Student's $t$ test (continuous variables) or Fisher's exact test (frequencies).

\section{RESULTS}

Of all 1618 neonates with structural congenital heart disease admitted within 30 days of birth to our institution since 2000, $238(15 \%)$ died. A small proportion $(n=61 ; 4 \%)$ received comfort care only, with no intended active management of the congenital heart lesion, owing to associated severe comorbidity. Time-related survival for the 1557 children who were actively managed for their condition is therefore shown in Figure 1. The overwhelming majority of deaths occurred in the first year of life (Figure 1); for those who survived to the age of 1 year, the hazard for death was low and constant thereafter $(<<1 \%$ per year).

\section{Section A}

Relationship between gestational age and survival. The distribution of gestational ages is depicted in Figure 2, A. Gestational age strongly influenced subsequent risk of death in a predictable way $(P<.0001)$. The relationship was nonlinear (Figure 2, B). Gestational ages less than approximately 36 weeks were associated with disproportionately worse survival, and for infants born at less than 32 weeks' gestation this relationship was especially marked. Interestingly, the impact of gestational age on survival was not limited to infants born prematurely. In a subanalysis of only the 1320 children born at term (37-42 weeks' gestation), gestational age was still a significant determinant of survival $(P=.0027)$ : infants born at 42 weeks were predicted to have $11 \%$ greater survival at 1 year versus those born at 37 weeks of gestation.

Relationship between birth weight and survival. The distribution of birth weights is depicted in Figure 3, A.
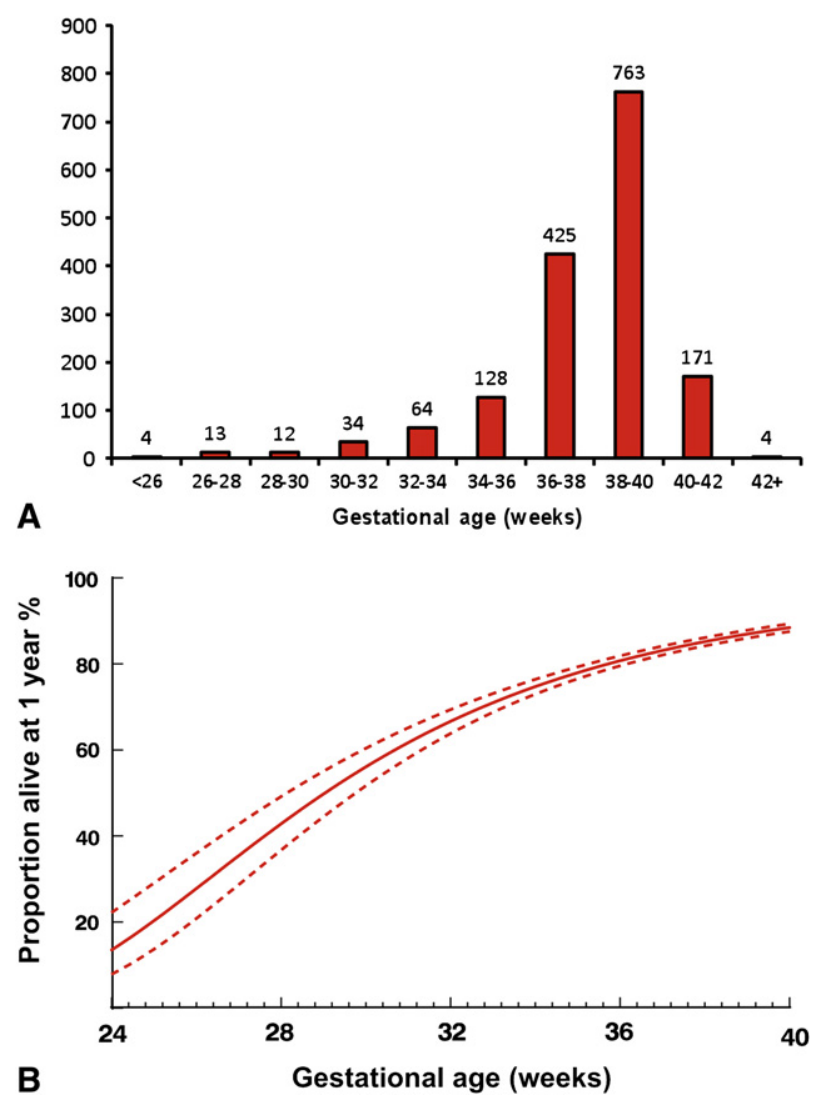

FIGURE 2. A, Histogram depicting the distribution of gestational ages in all 1618 study patients. Term is considered 37 to 40 weeks; 1,320 infants $(82 \%)$ were born at term, and $294(18 \%)$ were premature (only 4 infants were born after term). Of the premature children, 197 were born at less than 36 weeks, 49 at less than 32 weeks, and 13 at less than 28 weeks. B, Nomogram illustrating the nonlinear relationship between gestational age and survival in the 1557 actively managed children. This relationship held true (and was more pronounced) if all 1618 children were analyzed (including those 61 who received comfort care only).

Low birth weight-particularly below the normal range of 3.0 to $4.5 \mathrm{~kg}$ - strongly compromised survival $(P<.0001)$. The relationship was markedly nonlinear, and birth weight less than $2.0 \mathrm{~kg}$ was particularly associated with large decrements in survival (Figure 3, B). For infants weighing less than $1.0 \mathrm{~kg}$, fewer than half are predicted to survive to 1 year; between 1 and $1.5 \mathrm{~kg}$, survival is approximately $60 \%$; between 1.5 and $2.0 \mathrm{~kg}$, survival is approximately $75 \%$; and within the normal range of birth weights, late survival is approximately $90 \%$ (Figure 3, B). Therefore, for larger neonates, the survival differences related to birth weight were far less marked. Interestingly, however, in a subanalysis of only the 928 infants born within the normal weight range (3.0-4.5 kg), birth weight was still a significant determinant of survival $(P=.02)$.

Relative importance of gestational age and birth weight. When tested together, birth weight consistently predominated as the more reliable and dominant independent risk 

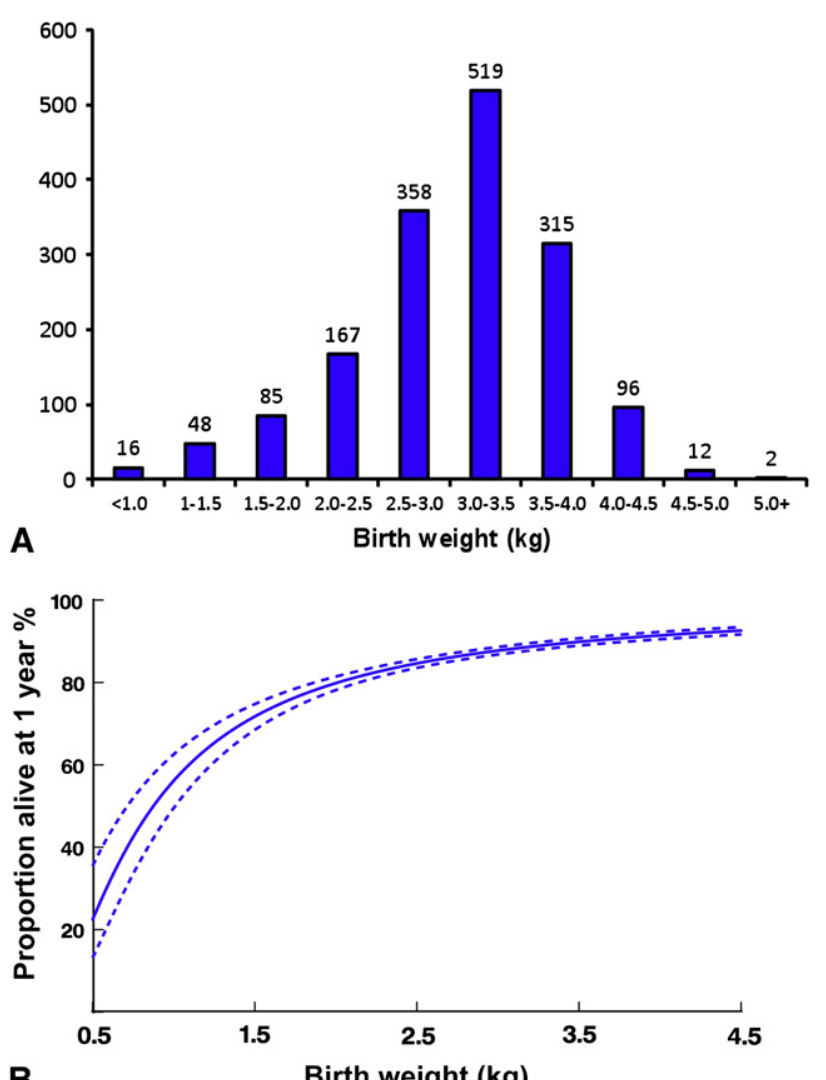

Birth weight $(\mathbf{k g})$

FIGURE 3. A, Histogram depicting the distribution of weights for all 1618 study patients. Normal birth weight is generally considered to be 3.0 to $4.5 \mathrm{~kg}$; $928(57 \%)$ infants were born with normal birth weight. Among the 652 born under $3.0 \mathrm{~kg}$ : 301 weighed less than $2.5 \mathrm{~kg}$ (low birth weight), 149 weighed less than $2.0 \mathrm{~kg}, 61$ weighed less than $1.5 \mathrm{~kg}$ (very low birth weight), and 16 weighed less than $1.0 \mathrm{~kg}$ (extremely low birth weight). B, Nomogram illustrating the nonlinear relationship between birth weight and survival in the 1557 actively managed children. This relationship held true (and was more pronounced) if all 1618 children were analyzed (including those 61 who received comfort care only).

factor over gestational age ( $\sim 99 \%$ bootstrap resamples vs $\sim 53 \%$ ). Furthermore, in larger multivariable models incorporating all available baseline patient-specific variables (diagnosis, genetic/chromosomal defects, and coexisting noncardiac morbidity), gestational age was replaced in the model by a range of colinear variables (Table 1). Therefore, much of the impact (variance) of low gestational age on outcome is attributable to these other risks. By contrast, low birth weight remained a strong and reliable independent risk factor for death $(P<.0001,99 \%$ bootstrap reliability); particularly so for birth weight less than $2.0 \mathrm{~kg}$.

\section{Section B}

The 149 children weighing less than $2.0 \mathrm{~kg}$ were classified according to the management strategy pursued $($ USUAL $=34 ;$ DELAYED $=46 ;$ OBSERVE $=30$;
TABLE 1. Risk factors for death in all 1557 of the 1618 study children who were actively managed (therefore excluding the 61 children who received comfort care only)

\begin{tabular}{lccc}
\hline & PE & $\boldsymbol{P}$ value & Reliability $(\%)$ \\
\hline Early risk factors & & & \\
$\quad$ Atrioventricular septal defect & 1.16 & $<.0001$ & 98 \\
Total anomalous PV connection & 1.35 & $<.0001$ & 98 \\
Pulmonary atresia, IVS & 1.19 & .0002 & 84 \\
Syndromic & 1.02 & .0007 & 78 \\
Cardiac arrest at time of diagnosis & 2.35 & $<.0001$ & 78 \\
Antenatal diagnosis & 0.50 & .0024 & 74 \\
Birth weight (kg) & -0.49 & $<.0001$ & 73 \\
LV hypoplasia & 1.63 & $<.0001$ & 65 \\
Interrupted aortic arch & 1.18 & .0097 & 59 \\
Apgar score at 1 minute & -0.15 & $<.0001$ & 51 \\
Gestational age & - & .57 & - \\
Late risk factors & & & \\
Congenital CNS defect & 3.11 & $<.0001$ & 50 \\
\hline
\end{tabular}

Gestational age was not a significant independent risk factor; when forced into the model, its level of significance was .57. The only risk factor with acceptable reliability associated with increased risk of late phase death was presence of a congenital CNS malformation. Similar analysis of all 1618 study children (including those 61 who received comfort care only) revealed precisely the same risk factors listed, with the addition of: presence of trisomy 13 (PE, $2.92 ; P<.0001$ ), presence of trisomy 18 (PE, 2.14; $P<.0001$ ), and presence of Turner syndrome (PE, 1.72; $P=.018$ ). $P E$ Parameter estimate; $P V$, Pulmonary vein; $I V S$, intact ventricular septum; $L V$, left ventricular; CNS, central nervous system.

$\mathrm{NON}-\mathrm{CV}=12$; WITHDRAWN $=27$ ). Characteristics of the 80 neonates whose management was either USUAL $(\mathrm{n}=34)$ or DELAYED $(\mathrm{n}=46)$ are given in Table 2. Although statistically significant differences between the groups are few, certain trends are apparent. In children managed according to USUAL strategies, there appears to be a higher prevalence of left-sided lesions, fewer associated congenital defects, and fewer baseline morbidities. In contrast, in infants in whom a DELAYED strategy was pursued, there was a higher frequency of right-sided lesions, associated congenital lesions, and baseline morbidities.

\section{Section C}

The univariate (unadjusted) difference in survival was not different between neonates managed according to USUAL decision strategies versus those whose intervention was DELAYED $(P=.88$ ) (Figure $4, A)$. Multivariable risk adjustment with baseline patient-specific variables revealed no significant impact of a USUAL versus DELAYED strategy $(P=.54)$. Finally, adjustment using patient-specific variables and propensity score revealed a tendency for slightly worse survival with a DELAYED strategy; however, this trend did not approach significance $(P=.65)$ (Figure $4, B$ ). Instead, important determinants of death in this population of actively managed neonates born weighing less than $2.0 \mathrm{~kg}$ included antenatal diagnosis $(P=.01$, $50 \%$ reliability) or presence of total anomalous pulmonary venous connection $(P=.003,50 \%)$, pulmonary atresia 
TABLE 2. Characteristics of the 80 infants with birth weight $<2 \mathbf{~ k g}$ who were actively managed according to either USUAL $(n=34)$ or DELAYED $(n=46)$ clinical paradigms

\begin{tabular}{|c|c|c|c|}
\hline & USUAL & DELAYED & $P$ value \\
\hline No. & 34 & 46 & - \\
\hline Dead & 8 & 11 & .97 \\
\hline Birth weight & $1.66 \pm 0.06$ & $1.44 \pm 0.05$ & .01 \\
\hline Gestational age & 32.8 & 32.4 & .62 \\
\hline Antenatal diagnosis & 7 & 13 & .60 \\
\hline Length of imposed delay & - & $8.0(1-32)$ & - \\
\hline \multicolumn{4}{|l|}{ Diagnosis } \\
\hline Isolated coarctation & 7 & 4 & .19 \\
\hline Coarctation + VSD & 3 & 1 & .31 \\
\hline Diffuse LVOTO & 3 & 0 & .07 \\
\hline LV hypoplasia & 3 & 1 & .31 \\
\hline Isolated aortic stenosis & 2 & 0 & .18 \\
\hline Isolated AVSD & 1 & 2 & .71 \\
\hline AVSD & 2 & 5 & .69 \\
\hline Simple TGA & 1 & 2 & .75 \\
\hline $\mathrm{TGA}+\mathrm{VSD}$ & 0 & 0 & - \\
\hline $\mathrm{TGA}+\mathrm{VSD}+\mathrm{PS}$ & 1 & 2 & .75 \\
\hline Truncus arteriosus & 2 & 4 & .64 \\
\hline TAPVC & 1 & 4 & .39 \\
\hline DORV & 0 & 6 & .04 \\
\hline Tetralogy of Fallot (PS) & 1 & 4 & .39 \\
\hline Tetralogy of Fallot (PA) & 2 & 4 & .64 \\
\hline Pulmonary atresia, IVS & 3 & 4 & .98 \\
\hline RV hypoplasia & 1 & 4 & .39 \\
\hline \multicolumn{4}{|l|}{ Acquired baseline comorbidity } \\
\hline Neurologic & 5 & 12 & .28 \\
\hline Respiratory & 8 & 14 & .61 \\
\hline Gastrointestinal & 2 & 10 & .06 \\
\hline Genitourinary & 0 & 2 & .51 \\
\hline Cardiorespiratory arrest & 1 & 0 & .43 \\
\hline Sepsis & 4 & 9 & .54 \\
\hline Any associated morbidity & 13 & 27 & .11 \\
\hline \multicolumn{4}{|l|}{ Associated congenital defects } \\
\hline Neurologic & 0 & 3 & .26 \\
\hline Respiratory & 0 & 1 & .39 \\
\hline Gastrointestinal & 0 & 6 & .04 \\
\hline Genitourinary & 3 & 10 & .14 \\
\hline Dysmorphic & 7 & 7 & .56 \\
\hline Syndromic & 0 & 6 & .04 \\
\hline Known gene/Ch defect & 4 & 10 & .37 \\
\hline Any associated defect & 4 & 19 & .006 \\
\hline
\end{tabular}

$V S D$, Ventricular septal defect; $L V O T O$, left ventricular outflow tract obstruction; $L V$, left ventricular; $A V S D$, atrioventricular septal defect; $T G A$, transposition of the great arteries; $P S$, pulmonary stenosis; $P A$, pulmonary atresia; $I V S$, intact ventricular septum; $\mathrm{Ch}$, chromosomal.

with intact ventricular septum $(P=.005,64 \%)$, or truncus arteriosus $(P=.03,79 \%)$.

Imposed delay. In the 46 children who had DELAYED management, the mean length of time until delayed intervention or death was 8.5 weeks (range, 1-32 weeks; Figure 5, A). During the growth period, $18(38 \%)$ patients sustained important new clinical complications (Table 3). Six $(13 \%)$ children died while waiting for their delayed
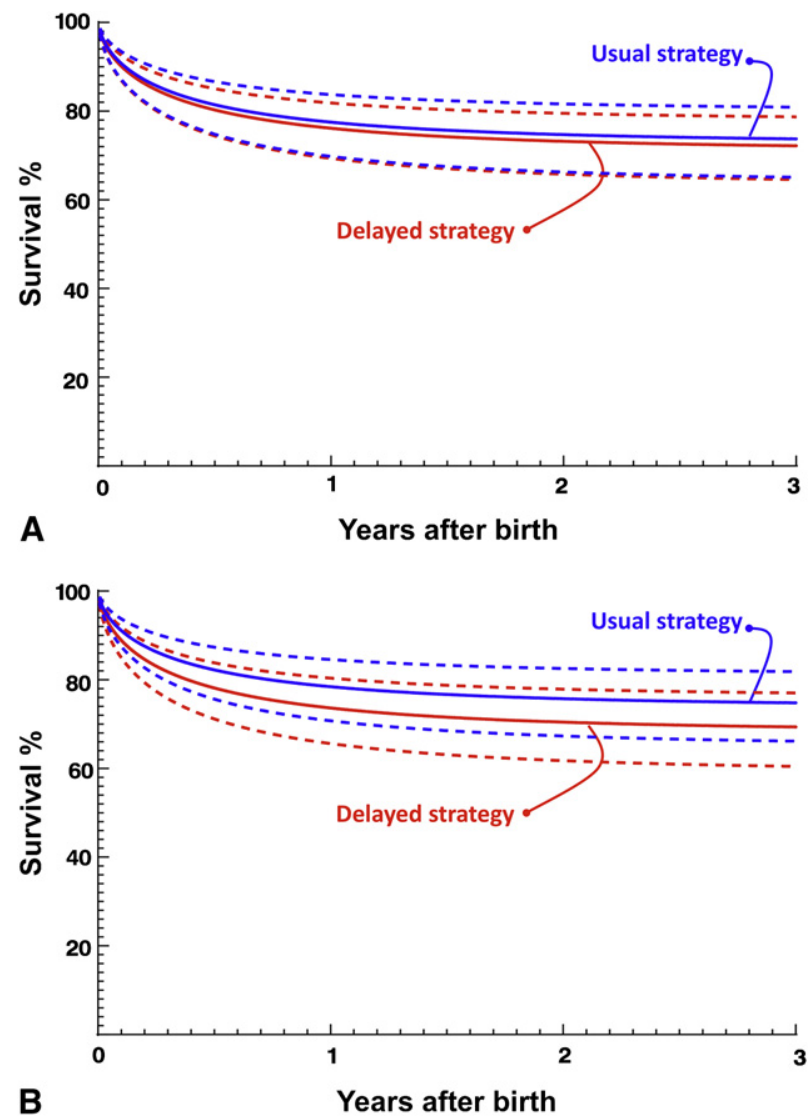

FIGURE 4. A, Univariate (unadjusted) comparison of survival between children managed according to USUAL $(\mathrm{n}=34)$ decision strategies versus DELAYED $(n=46)$. Survival in all 80 children was modeled parametrically and stratified according to decision strategy. Survival was identical $(P=.88)$. B, Propensity-adjusted comparison of survival between children managed according to USUAL decision strategies versus DELAYED. The survival model for all 80 children was subjected to multivariable regression analysis including baseline patient-specific variables and a propensity score. Survival differences were not significant $(P=.65)$. Solid lines represent parametric determinants of continuous point estimates. Dashed lines enclose $70 \%$ confidence intervals.

intervention (Table 4). Four of these 6 had cyanotic lesions, 3 of whom were supported with long-term prostaglandins. Three of these 4 had fatal cardiorespiratory arrests while receiving prostaglandin support and the fourth had a massive thromboembolic stroke complicated by intractable seizures. The remaining 2 deaths resulted from multiorgan failure and an insidious realization that long-term prognosis was futile; active care was withdrawn. There was no discernible pattern regarding the duration that these 6 children waited before dying $(P=.87)$. Although numbers were small, logistic risk factors for death while waiting included a diagnosis of pulmonary atresia with intact ventricular septum $(P=.02$; parameter estimate, +3.2$)$, presence of syndromic features $(P=.01$; parameter estimate, +3.4$)$, and sepsis $(P=.03$; parameter estimate, 2.6$)$. 

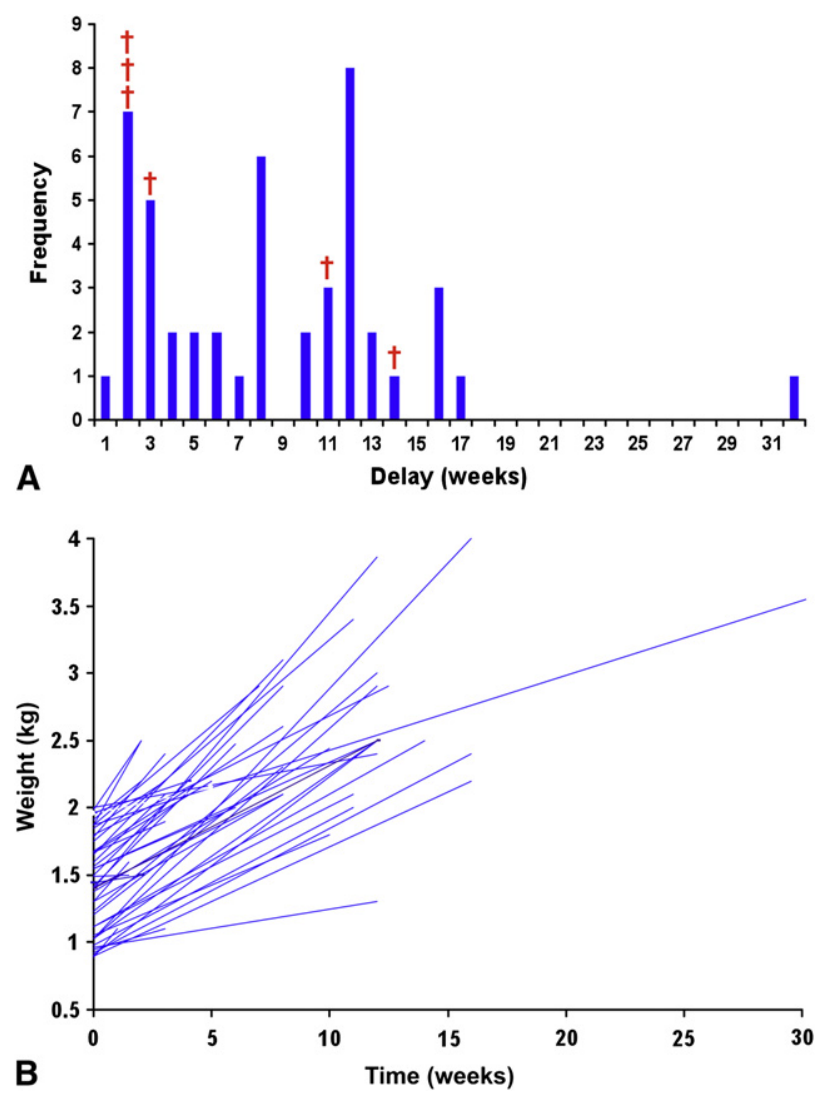

FIGURE 5. A, Histogram depicting the distributions of the lengths of delay experienced by the 46 infants in whom a DELAYED strategy was pursued. The timing of the 6 deaths that occurred are depicted by the red symbol. B, Time-related rate of growth for the 46 individual patients in the DELAYED group. These individual growth rates were subsequently modeled collectively as a repeated-measures generalized estimating equation to explore the growth rate further. The mean growth rate was approximately $95 \mathrm{~g}$ per week $(95 \%$ confidence interval, $72-117 \mathrm{~g} ; P<.0001)$.

During the period of imposed delay for growth and maturation, the mean rate of growth was approximately $95 \mathrm{~g}$ per week $(95 \%$ confidence interval, $72-117 \mathrm{~g} ; P<.0001$; Figure $5, B)$. Trends were sought to identify lesions associated with faster or slower growth rates, inasmuch as rate of growth would have important clinical implications for the cumulative risk imposed by a DELAYED strategy. Interestingly, several lesions (tetralogy of Fallot, atrioventrciular canal defects, and total anomalous pulmonary venous connection) were associated with faster than average growth rates (Table 5). By contrast, truncus arteriosus, aortic coarctation, and pulmonary atresia with intact ventricular septum were all associated with slower than average growth rates.

During the period of early recovery after intervention, the prevalence of important clinical complications was similar in both patient groups (Table 3). Importantly, the incidence of cerebral complications occurring in children who underwent USUAL intervention was not significantly elevated; of the 3 cerebral bleeds that did occur in this group, 2 occurred on extracorporeal membrane oxygenation support. Among children managed with a DELAYED strategy, several children who experienced complications during the period of delay also experienced complications after intervention. Therefore, the proportion of children free from any new important complication occurring after the time of cardiac decision strategizing was $68 \%(23 / 34)$ and $28 \%(13 / 46)$ for the USUAL and DELAYED groups, respectively $(P<.001)$. Consequently, the overall acquired burden of complications was greater for the DELAYED group than the USUAL group, although overall survival was not different.

\section{DISCUSSION}

In our experience, high-risk neonates born weighing less than $2.0 \mathrm{~kg}$ who received intentional delays in treatment to promote growth and maturation had survival comparable with that of similar neonates who received timely treatment according to usual decision-management strategies. Infants who received a delayed approach tended to have greater baseline morbidity and associated noncardiac defects. The mortality burden of these problems during the period of growth did not appear to outweigh the intuitively elevated risk of intervening early on low-birth-weight infants. Strategizing for premature or low-birth-weight neonates with congenital heart disease has long been a contentious and unresolved issue; our experience does not lead us to strongly recommend either an early interventional or delayed interventional approach over the other, although the overall burden of complications appears to be significantly greater in children managed with a delayed strategy.

It was of interest to us that low birth weight was consistently a stronger determinant of poor outcome than prematurity per se. Our regression explorations imply that the clinical impact of prematurity is largely represented by other factors with strong colinear associations: certain unfavorable diagnoses, syndromes, and clinical status. The implication is therefore that a premature infant (with birth weight $>2.0 \mathrm{~kg}$ ) in reasonable clinical condition may not be at particularly elevated risk compared with a similarsized term child. In contrast, low birth weight appears to confer high early surgical risk over and above other markers of poor prognosis. Specific reasons for and the nature of this risk are not well understood but may relate to technical factors as well as nutrition, ${ }^{7}$ immunologic fitness, ${ }^{8}$ fluid balance, and cardiovascular physiology. Low birth (or operative) weight has consistently been noted to be a risk factor in other large lesion- or procedure-specific analyses of surgery in neonates with congenital heart disease. ${ }^{5,9,10}$ Irrespective of low weight as an independent statistical risk, whether its effect is completely mitigated in the clinical world by weight gain is not certain. However, it is this logic that forms the basis of a delayed therapeutic strategy. 
TABLE 3. New important clinical complications sustained after the time of cardiac decision strategizing in children treated by USUAL and DELAYED strategies

\begin{tabular}{|c|c|c|c|c|}
\hline \multirow[b]{2}{*}{ Important clinical complications } & \multicolumn{2}{|c|}{ Before intervention (after decision strategizing) } & \multicolumn{2}{|c|}{ After intervention } \\
\hline & USUAL & DELAYED & USUAL & DELAYED \\
\hline Patients having complications & 0 & 18 & $11^{*}$ & $23^{*}$ \\
\hline Total complications (by system) & - & 33 & $18^{*}$ & $30 *$ \\
\hline Death & - & 6 & $8 \dagger$ & $5 \dagger$ \\
\hline Cardiac arrest/shock & - & 7 & 3 & 2 \\
\hline Pneumonia/ventilator-dependent & - & 7 & 1 & 4 \\
\hline Gastrointestinal & - & 5 & 3 & 5 \\
\hline Renal & - & 2 & 0 & 1 \\
\hline Cerebral & - & 2 & $3(\mathrm{ECMO}=2)$ & 2 \\
\hline Thrombosis/hematologic & - & 4 & 3 & 6 \\
\hline Systemic sepsis & - & 7 & 3 & 9 \\
\hline
\end{tabular}

$E C M O$, Extracorporeal membrane oxygenation. *Not statistically significant between groups. †Total postoperative deaths (early and late).

Six children died during an intended period of growth: 4 directly attributable to the cardiovascular lesion and 2 attributable to escalating multisystem comorbidity. It is difficult or impossible to judge retrospectively whether early cardiac repair would have been feasible in these latter 2 infants. However, it is of interest that 4 deaths occurred in cyanotic right-sided lesions, 3 in the presence of longterm prostaglandin therapy. A message penetrating through our regression analyses may be that despite gaining weight fairly rapidly, infants with right-sided cyanotic lesions are in a more precarious condition during the growth period and might therefore benefit instead from early therapeutic approaches. By contrast, left-sided and mixing lesions (coarctations, total anomalous pulmonary venous connection, truncus arteriosus, and transposition of the great arteries) may be "safer" during the growth period and therefore more suitable for a delayed approach.

The incidence of complications sustained during the period of growth was high (38\%) and affected all (frequently multiple) bodily systems. To contextualize this, it would be interesting to know the incidence and spectrum of complications occurring in low-birth-weight newborns without congenital heart disease in an intensive care environment. Many of the complications (necrotizing enterocolitis, stroke, pneumonia, and thrombosis) are endemic to neonatal intensive care environments. ${ }^{11-14}$ Minimizing the incidence and severity of noncardiac morbidities should clearly be the goal of any strategy of imposed therapeutic delay for growth purposes. During delay for growth, weight gain should be closely scrutinized. In our experience, the mean rate of growth was $95 \mathrm{~g}$ per week, although this ranged widely: some lesions demonstrated almost twice this growth rate, whereas others were associated with less than half this rate of growth. Intuitively, it seems sensible that a poor rate of growth should prompt reevaluation of the clinical decision to pursue a delayed strategy.

When considering the risk-hazard equation for very small neonates, it is important to recognize that if the increased operative risk of early intervention in low-birthweight neonates is mitigated, then imposed delays become superfluous. Impressive results have been reported for repairs for congenital heart defects on progressively smaller infants including those weighing less than $2.5 \mathrm{~kg},{ }^{15,16}$ less than $2.0 \mathrm{~kg},{ }^{17}$ less than $1.5 \mathrm{~kg},{ }^{18}$ and even as low as 0.7 $\mathrm{kg} .{ }^{16}$ If noncardiovascular complications of prematurity and low birth weight remain largely unresolved, it is likely that, over time, the risk-hazard equation will gradually swing in favor of progressively earlier intervention.

Finally, it is noteworthy, and academically problematic, that particularly small infants presenting as a decisionmanagement dilemma are relatively infrequent. In our quaternary institution with a broad referral base and annual

TABLE 4. Summary of the 6 children who died during a DELAYED strategy, before definitive cardiac repair

\begin{tabular}{|c|c|c|c|c|c|c|}
\hline Case & $\begin{array}{c}\text { Birth } \\
\text { weight }(\mathrm{kg})\end{array}$ & $\begin{array}{c}\text { Time to } \\
\text { death (wk) }\end{array}$ & Diagnosis & $\begin{array}{c}\text { Therapy } \\
\text { whilegrowing }\end{array}$ & $\begin{array}{l}\text { Complications } \\
\text { while growing }\end{array}$ & Mode of death \\
\hline 1 & 1.5 & 1.5 & Hemitruncus & Supportive & $\begin{array}{l}\text { Intra-ventricular hemorrhage, } \\
\text { NEC, pneumonia }\end{array}$ & Withdrawn \\
\hline 2 & 0.9 & 3 & TOF & $\mathrm{PGE}_{1}$ & Cerebral infarct, NEC & Status epilepticus \\
\hline 3 & 1.7 & 11 & TOF & Supportive & Systemic sepsis, pneumonia & Cardiorespiratory arrest \\
\hline 4 & 1.3 & 1.5 & PAIVS & $\mathrm{PGE}_{1}$ & Apnea, desaturations & Cardiac arrest \\
\hline 5 & 1.4 & 2 & PAIVS & $\mathrm{PGE}_{1}$ & - & Cardiorespiratory arrest \\
\hline 6 & 1.1 & 14 & Scimitar, VSD & Supportive & $\begin{array}{l}\text { Pneumonia, tracheomalacia, } \\
\text { multiple congenital co-morbidities }\end{array}$ & Withdrawn \\
\hline
\end{tabular}

TOF, Tetralogy of Fallot; PAIVS, pulmonary atresia with intact ventricular septum; $V S D$, ventricular septal defect; $P G E_{1}$, prostaglandin $\mathrm{E}_{1} ; N E C$, necrotizing enterocolitis. 
TABLE 5. Summary of trends in the rate of growth for the 46 children who underwent a DELAYED strategy

\begin{tabular}{|c|c|c|}
\hline & Tendency for birth weight & Rate of growth \\
\hline AVSD & - & $\begin{array}{l}\text { Increase growth rate } \\
(\sim 150 \% ; P=.045)\end{array}$ \\
\hline Tetralogy (PS/PA) & - & $\begin{array}{l}\text { Increased growth rate } \\
(\sim 140 \% ; P=.033)\end{array}$ \\
\hline TAPVC & $\begin{array}{l}\text { Trend toward smaller at birth } \\
(\sim 300 \mathrm{~g} ; P=.07)\end{array}$ & $\begin{array}{l}\text { Increased growth rate } \\
(\sim 150 \%) ; P=.024)\end{array}$ \\
\hline Truncus arteriosus & - & $\begin{array}{l}\text { Reduced growth rate } \\
(\sim 50 \% ; P=.034)\end{array}$ \\
\hline Coarctation & $\begin{array}{l}\text { Trend toward bigger at birth } \\
(\sim 300 \mathrm{~g}, P=.03)\end{array}$ & $\begin{array}{l}\text { Reduced growth rate } \\
(\sim 50 \% ; P<.0001)\end{array}$ \\
\hline $\begin{array}{l}\text { Pulmonary } \\
\text { atresia, IVS }\end{array}$ & - & $\begin{array}{l}\text { Slightly reduced rate } \\
(\sim 70 \% ; P .022)\end{array}$ \\
\hline
\end{tabular}

Time-related rate of growth was explored using parametric generalized estimating equations (adjusted for repeated measures). For the group as a whole, the mean starting weight was $1.51 \mathrm{~kg}$, and the average growth rate was $95 \mathrm{~g}$ per week. All diagnostic categories and comorbidities were individually explored, and a summary of significant trends is presented here. Magnitude of growth rates is expressed as a percentage above or below the mean of $95 \mathrm{~g}$ per week and is derived from the parameter estimates of the regression equations. AVSD, Atrioventricular septal defect; $P S$, pulmonary stenosis; $P A$, pulmonary atresia; $T A P V C$, total anomalous pulmonary venous connection; IVS, intact ventricular septum.

surgical case volume exceeding 600 , we identified only 80 such children in over a decade. Prospective investigations into timing of intervention, although appealing, are therefore impractical and unlikely. Instead, we must rely on retrospective appraisal of our experiences. Similar retrospective approaches have been useful in the risk-hazard quantification of staged versus primary repair of particular congenital lesions (tetralogy of Fallot, ${ }^{19}$ pulmonary atresia with ventricular septal defect and collaterals, ${ }^{20}$ and others ${ }^{21}$ ). However, exploring strategic options in low-birth-weight children is further hampered by their heterogeneity of diagnoses and comorbidities. The low-birth-weight infants in our series had a high incidence of congenital noncardiac defects, syndromes, and acquired comorbidities such that statistical adjustment can become difficult. We acknowledge the problems of patient diagnostic and clinical heterogeneity in our analysis. It is for these reasons that we explored impact of delayed intervention using several unadjusted and adjusted techniques. Nevertheless, multivariable and propensity score methodology can only make crude adjustments, particularly if differences between groups are real and pronounced. Although reassuring that outcome differences were not observed irrespective of analytic approach, the subtle differences in diagnosis and comorbidity are likely of real clinical importance for decision strategizing. The comorbidities in some of the DELAYED children may have (unbeknown to the retrospective researcher) prevented early intervention and therefore have dictated a delayed approach; it is impossible to fully account for this.

In summary, low birth weight of less than $2.0 \mathrm{~kg}$ is a strong, reliable, and independent predictor of poor outcome for neonates born with congenital heart lesions. Prematurity is a less important risk factor for death. For high-risk low-birth-weight children, a clinical dilemma exists: whether to pursue early (higher-risk) therapeutic intervention or otherwise impose a period of delay for growth and maturation before (presumably lower-risk) intervention. In the past decade of our experience, imposed delays were associated with nonfatal complications in approximately one third and death during the growth period in $13 \%$. However, when comparing neonates with DELAYED intervention versus USUAL early intervention, late survival was comparable in both unadjusted and adjusted analyses. Strategizing for premature or low-birth-weight neonates with congenital heart disease has long been a contentious and unresolved issue; our experience does not lead us to strongly recommend either an early interventional or delayed interventional approach over the other. Finally, although overall survival for children managed via a delayed strategy was not compromised, it is noteworthy that the total complication burden experience by these children was significantly greater.

\section{References}

1. Dimmick S, Walker K, Badawi N, Halliday R, Cooper SG, Nicholson IA, et al Outcomes following surgery for congenital heart disease in low-birthweight infants. J Paediatr Child Health. 2007;43:370-5.

2. Oppido G, Pace Napoleone C, Formigari R, Gabbieri D, Pacini D, Frascaroli G, et al. Outcome of cardiac surgery in low birth weight and premature infants. Eur J Cardiothorac Surg. 2004;26:44-53.

3. Blackstone EH, Naftel DC, Turner MEJ. The decomposition of time-varying hazard into phases, each incorporating a separate stream of concomitant information. J Am Stat Assoc. 1986;81:615-24.

4. Kalbfleisch JD, Prentice RL. The statistical analysis of failure time data. New York: John Wiley; 1983.

5. Hickey EJ, Caldarone CA, Blackstone EH, Lofland GK, Yeh T Jr, Pizarro C, et al. Critical left ventricular outflow tract obstruction: the disproportionate impact of biventricular repair in borderline cases. J Thorac Cardiovasc Surg. 2007;134: 1429-36; discussion 1436-7.

6. Breiman L. Bagging predictors. Machine Learning. 1996;24:123-40.

7. Schutzman DL, Porat R, Salvador A, Janeczko M. Neonatal nutrition: a brief review. World J Pediatr. 2008;4:248-53.

8. Hadzimuratovic E, Dinarevic SM, Hadzimuratovic A. Sepsis in premature newborns with congenital heart disease. Congenit Heart Dis. 2010;5:435-8.

9. Ashburn DA, McCrindle BW, Tchervenkov CI, Jacobs ML, Lofland GK, Bove EL, et al. Outcomes after the Norwood operation in neonates with critical aortic stenosis or aortic valve atresia. J Thorac Cardiovasc Surg. 2003;125:1070-82.

10. Bove T, Francois K, De Groote K, Suys B, De Wolf D, Verhaaren H, et al. Outcome analysis of major cardiac operations in low weight neonates. Ann Thorac Surg. 2004;78:181-7.

11. Saigal S, Doyle LW. An overview of mortality and sequelae of preterm birth from infancy to adulthood. Lancet. 2008;371:261-9.

12. Chen J, Zimmerman RA, Jarvik GP, Nord AS, Clancy RR, Wernovsky G, et al Perioperative stroke in infants undergoing open heart operations for congenital heart disease. Ann Thorac Surg. 2009;88:823-9.

13. Motta M, Bagna R, Saracco P, Casani A, Pinto L, Testa M. Neonatal thrombosis Minerva Pediatr. 2010;62:117-20.

14. Sekar KC. Iatrogenic complications in the neonatal intensive care unit. J Perina tol. 2010;30(Suppl):S51-6.

15. Haas F, Goldberg CS, Ohye RG, Mosca RS, Bove EL. Primary repair of aortic arch obstruction with ventricular septal defect in preterm and low birth weight infants. Eur J Cardiothorac Surg. 2000;17:643-7.

16. Reddy VM, McElhinney DB, Sagrado T, Parry AJ, Teitel DF, Hanley FL. Results of 102 cases of complete repair of congenital heart defects in patients weighing 700 to 2500 grams. J Thorac Cardiovasc Surg. 1999;117:324-31. 
17. Sudarshan CD, Cochrane AD, Jun ZH, Soto R, Brizard CP. Repair of coarctation of the aorta in infants weighing less than 2 kilograms. Ann Thorac Surg. 2006;82: 158-63.

18. Reddy VM, Hanley FL. Cardiac surgery in infants with very low birth weight. Semin Pediatr Surg. 2000;9:91-5.

19. Van Arsdell GS, Maharaj GS, Tom J, Rao VK, Coles JG, Freedom RM, et al. What is the optimal age for repair of tetralogy of Fallot? Circulation. 2000; 102(19 Suppl. 3):III123-9.

20. Reddy VM, McElhinney DB, Amin Z, Moore P, Parry AJ, Teitel DF, et al. Early and intermediate outcomes after repair of pulmonary atresia with ventricular septal defect and major aortopulmonary collateral arteries: experience with 85 patients. Circulation. 2000;101:1826-32.

21. Najm HK, Van Arsdell GS, Watzka S, Hornberger L, Coles JG, Williams WG. Primary repair is superior to initial palliation in children with atrioventricular septal defect and tetralogy of Fallot. J Thorac Cardiovasc Surg. 1998;116: 905-13.

\section{Discussion}

Dr Scott M. Bradley (Charleston, SC). That was an excellent presentation on a topic that is clearly a challenge to everyone in the room. I thought that the information on the relative importance of low birth weight versus prematurity was particularly interesting, as was the growth velocity that can be expected in these low-birthweight babies. I do have a couple of questions about the ways in which you have chosen to analyze your data.

The first question has to do with the 2 groups, which you call "early" and "delayed." This differentiation was based on your retrospective assessment of the goal of the management team at the time that the patient presented. I commend you for going through all of those charts and figuring that out. Nonetheless, some of the patients in the delayed group underwent intervention within the first 1 to 2 weeks of life, which would not be considered very delayed and certainly not long enough to expect much growth. Do you have any information for us on the ages at intervention in the early group and whether there was overlap with what you call the delayed group?

Dr Hickey. Thank you very much, Dr Bradley, for your questions.

In terms of the categorization of patients, it is very difficult retrospectively and it would be great to do a prospective study, but that is simply impractical or impossible.

Rather than opt for procedure-based categories, for example, palliation or repair, we wanted to categorize in terms of completely deviating from the strategy. As best as I can, I think I have done that.

In terms of the ages of the 2 groups, patients in the early group were generally all intervened on the next available appropriate clinical slot in the neonatal period after presenting, so within the first 2 to 3 weeks after birth, whereas the mean age at intervention for the delayed group was on average about 8 weeks later. Of course, we had a number of deaths even within 1 to 2 weeks of being delayed.

Dr Bradley. It appears that if the early group was intervened on within the first 2 to 3 weeks after birth, there was significant overlap between the early and the delayed groups. That would probably be good information to put in the article.

Would it have been more clear-cut to simply analyze the patients on the basis of their age at intervention as either a continuous or a categorical variable, rather than trying to look back and determine the intentions of the team at the time, which was up to 10 years ago?

Dr Hickey. Certainly you can look at age at intervention, and we have done so in several other series. We know age at intervention is a very important variable. We specifically wanted to go back to the decision-making algorithm from the outset and make a decision-making analysis rather than just a risk-hazard-based analysis in retrospect.

Dr Bradley. I want to ask about a topic that you mentioned-the type of interventions in the 2 groups. Many of these patients were candidates for more than 1 intervention, for example, in tetralogy of Fallot, complete repair versus palliation with a shunt, in hypoplastic left heart syndrome, Norwood versus hybrid procedure. I assume that some of your patients underwent catheterization interventions, for example, balloon septostomy in patients with transposition and balloon aortic valvotomy in patients with aortic stenosis. Other catheterization interventions, while not routine, could be considered in selected patients, for example, stenting the outflow tract or the ductus in tetralogy or pulmonary atresia. Do you have any analysis of the breakdown of the types of intervention in your 2 groups: complete repair versus palliation versus catheterization laboratory?

Dr Hickey. It was our hope and intention from the outset that we might end up with some homogeneous patient groups, either in terms of diagnosis or in terms of interventional strategy, that we could then compare. It was very clear from the outset, though, that that was not going to be the case. This is actually quite an uncommon problem if you consider 80 patients over 10 years. We have a catchment area of about 13 million at Toronto. This is actually quite an unusual dilemma, although it is one we are all very familiar with. That is why we have such a heterogeneous bunch. Therefore, it is very difficult to compare one specific interventional strategy versus another. We have not been able to do that.

In terms of the range of options for each child, that exists for a normal-birth-weight child. Even for a child of normal birth weight with tetralogy or truncus or whatever, there can be different management strategies. We were only interested if we completely deviated and did something different because of the very low birth weight.

Dr Bradley. Fair enough. I think it would be useful to include some information on whether you are talking about complete repairs or palliation, especially in the early group. Although you did factor patient diagnosis into your risk-adjustment analyses, I would think you could enter complete repair versus palliation into that analysis as well.

One final question: You have given us some valuable information on the growth velocity that we can actually expect in these low-birth-weight patients if we do decide to take a wait-and-feed approach. Growth is generally more effective on enteral feeding than on total parenteral nutrition. However, many practitioners are reluctant to enterally feed a premature, low-birth-weight baby, especially if the infant is receiving a prostaglandin infusion. Can you tell us how the babies in your delayed group were approached in terms of feeding to achieve growth, from your review of charts, or what your approach would be now, particularly in a baby who is receiving a prostaglandin infusion?

Dr Hickey. Unfortunately, I cannot elaborate much on that information because we did not have those data. Nor am I, by any 
stretch of the imagination, an expert on nutrition in these small infants. Nevertheless, in our intensive care unit we aggressively try to enterally feed all our infants unless there is a strong reason to do otherwise. Obviously, we use fortified feeds with dietician advice and all that sort of thing.

In terms of the difference between the growth rates, I was most struck by the difference, especially the infants with coarctation, which seemed to grow at a very high level of statistical significance at a very low rate. That to us suggests that of all the groups, patients with coarctation are maybe the ones on whom we should operate early. Indeed, that is what we do now routinely, down to 1.4 to $1.5 \mathrm{~kg}$.

I have just one final comment about your previous comments about palliation: At Sick Kids we have a very high threshold for palliative strategies. In the mid-1990s we switched, for example, from using any shunts for patients with tetralogy; it is rare, in fact, that we use bands or shunts in children now. Indeed, in this series they were very infrequent occurrences.

The data on long-term prostaglandin therapy, especially, is encouraging us to now explore other catheter-based approaches that can be used instead of long-term prostaglandin, especially subxiphoid approaches for tiny infants.

Dr Bradley. Fair enough. I think it is a very nice study. It is a relatively large group of patients with these issues. If you could provide some of this additional information in the article, it would be of interest to the readers.

Dr V. Mohan Reddy (Stanford, Calif). Dr Hickey, I would like to ask you a few questions. I know you looked at a lot of risk factors, but did you look at patients who were dependent for a prolonged period for mechanical ventilation or prostaglandins versus patients who are not dependent?

Dr Hickey. As subgroups, no, but they were both included as risk factors. We had acquired respiratory morbidity as a risk factor from the outset as baseline.

Dr Reddy. From the data, I could see that patients whose treatment was delayed had a significantly higher incidence of complications and there was also some mortality.

Dr Hickey. That is true.

Dr Reddy. But overall, there was no difference. What do you think accounted for the mortality in the early group to equalize it?

Dr Hickey. Intuitively, the assumption is that intervening in very small children is of elevated risk. We assume that the greater morbidity and mortality burden is in some way outweighed by the risk of intervening on these very small children.

Equally, we fully acknowledge that there are important differences within the patient groups, which is why we have tried to look at it in multiple different ways; but we still are not seeing an important difference between the 2 strategies.

Dr Reddy. Most likely, it could be technical. As with all technical operations, we gradually get better when we do the operation over time. I can assure you that even though the patient's weight increases from $1.5 \mathrm{~kg}$ to $2 \mathrm{~kg}$ or $2.2 \mathrm{~kg}$, the heart is not going to be much bigger than $10 \mathrm{mg}$ or $20 \mathrm{mg}$. Thus, I do not think it technically makes a huge difference. I think it is more in the mind than in actually doing the operation.

Dr Hickey. In terms of the risk of actually performing the operation, I agree, the technical aspects are very valid. Furthermore, certainly most here will know that your group at Stanford has managed to mitigate some of these issues, perhaps because of your experience with operating on fetal animals. You are much more attuned to operate on the infant weighing 1.1 to $1.2 \mathrm{~kg}$. Those are technical hurdles that others would have to overcome if they adopt that aggressive early approach.

However, certainly these smaller children are also physiologically different. There are immunologic risk factors, there are nutrition factors, they are much more prone to other complications, cerebral bleeds, that sort of thing, and so there are differences.

There is just one thing about this weight that I find fascinating. I have done subanalyses looking at the normal-birth-weight range, and even within the normal-birth-weight range, birth weight is a very strong determinant of risk, which is a very curious and interesting fact.

Dr Reddy. I think this is very important information to have available. However, I personally think that the patient should be individualized, not necessarily bunched into 1 of 2 categories, early and late or left-sided versus right-sided lesions. If the patients are dependent on a ventilator or requiring prolonged prostaglandins in the infusions, then we would generally tend to intervene. However, if the patient can be extubated and can be fed normally or can be taken off prostaglandin, I think the operation can certainly be delayed.

Dr Hickey. We would agree with you. We do not think our data can strongly advocate for one approach or the other, so we agree that the approach needs to be individualized. We also will intervene very early on very small patients with truncus or coarctation if we think that that child clinically is of acceptable risk to undergo an operation early. However, we are also reassured that if we choose to take a delayed approach, we are not taking on an excessive morbidity risk.

Dr Reddy. I also think more recent data suggest that the gestational age may have an impact on the neurologic injury and the brain maturation. That might be a more common factor for us to delay surgery in these patients, if we can safely.

Dr Hickey. Certainly. Dr Gaynor's group has done a lot of work showing very nicely that babies born at term with certain lesions are developmentally very immature, and that is a strong determinant of neurologic injury. Therefore, although we have focused on survival as the end point, we have not taken into account the morbidity burden in the long-term with either strategy, and that may be just as important.

Dr Reddy. One last question. Do you have any plans to do a prospective study in this regard?

Dr Hickey. I think the numbers that we have generated, 80 over 10 years from 1600 patients, really preclude that.

Dr Frank A. Pigula (Boston, Mass). My question is whether it is really fair to equate weight gain with growth in children who are receiving prostaglandins and are intubated with various means of nutritional support. I am not sure that they are really the same thing in those patients.

My other comment is that in analysis of our unit with these patients, their gestational age has been more important than their size. We can operate on very small patients, but we cannot make them older when we operate on them. Could you please address the age versus size issue?

Dr Hickey. When we pitched prematurity, that is, gestational age to birth weight, consistently birth weight was the more reliable determinant. That is because prematurity, although very important, 
as our data showed, is important because of the whole host of problems that come with it-certain lesions, certain other comorbidities, certain genetic syndromes, and such like. That's what the data were telling us was accounting for the risk of prematurity. Birth weight per se is a more reliable determinant as an independent risk factor for death.

Dr Pigula. That is interesting. That is a little bit counter to what we have seen in our group.

Dr Christian Pizarro (Wilmington, Del). That was a beautiful job. I am unclear about how patients were fed and how the choice was made. I saw you encountered a lot of gastrointestinal complications. A common problem we all face is that we see a tiny little baby and want to use enteral feeds, but we are hesitant, particularly in someone who has a shunt at the arterial level, such as an infant with truncus or hypoplastic left heart syndrome. What was the choice regarding feeding or nutrition in those patients, and could that be in any way related to the speed of weight gain?

Dr Hickey. That is entirely possible. I do not have all the data on the mechanisms of which patients were fed. Certainly gastrointestinal complications were common, as you expect in these very small children. We try to feed them enterally if at all possible to avoid necrotizing enterocolitis and other complications, but I do not have the specifics of that information.

In terms of weight gain, I am not sure what actually gave rise to the differences that we saw in weight gain. However, the category that really stuck out was patients with coarctation. They are not normally the infants who have all the other comorbidities, and yet their weight gain was very poor to a high level of significance. 
The Hospital for Sick Children 2000-2010

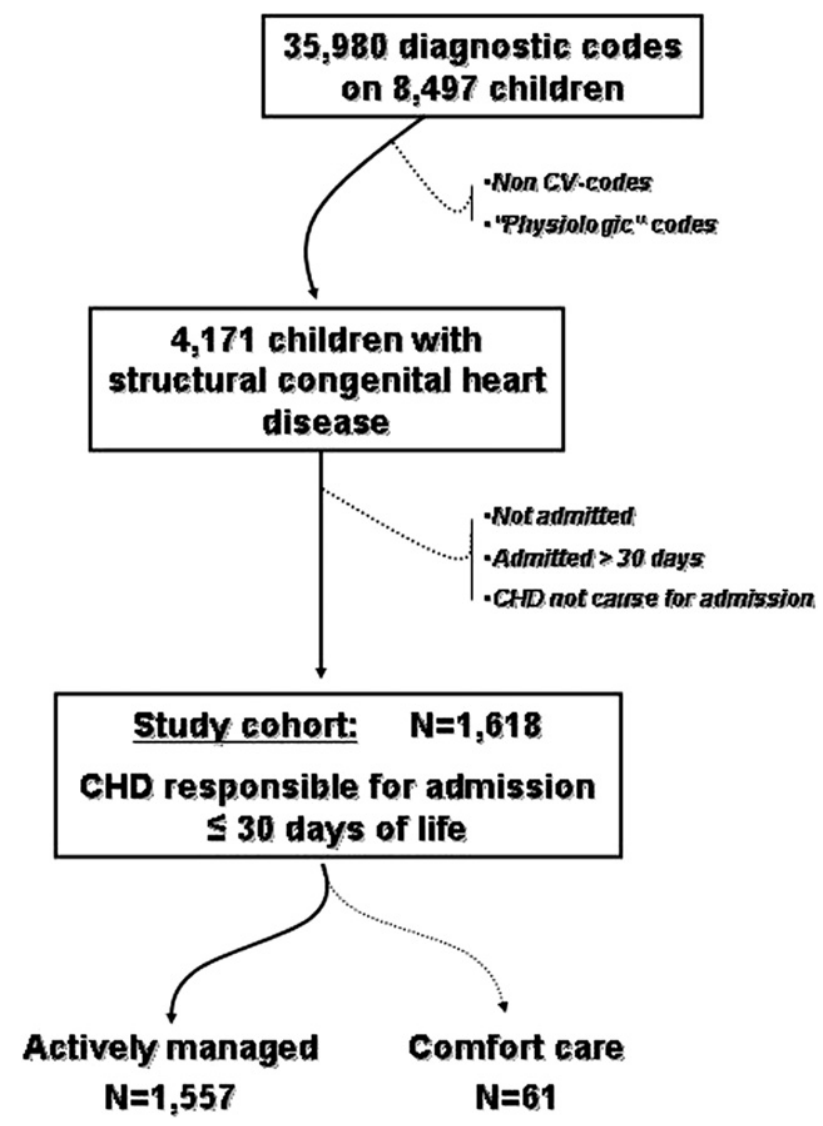

FIGURE E1. Overview of the study cohort. $C V$, Cardiovascular; $C H D$, congenital heart disease. 